\title{
Formation and stabilization of reverted austenite in supermartensitic stainless steel
}

\author{
Nießen, Frank; Grumsen, Flemming Bjerg; Hald, John; Somers, Marcel Adrianius Johannes
}

Published in:

Metallurgical Research and Technology

Link to article, DOI:

$10.1051 / \mathrm{metal} / 2018051$

Publication date:

2018

Document Version

Peer reviewed version

Link back to DTU Orbit

Citation (APA):

Nießen, F., Grumsen, F. B., Hald, J., \& Somers, M. A. J. (2018). Formation and stabilization of reverted austenite in supermartensitic stainless steel. Metallurgical Research and Technology, 115(4), [402]. https://doi.org/10.1051/metal/2018051

\section{General rights}

Copyright and moral rights for the publications made accessible in the public portal are retained by the authors and/or other copyright owners and it is a condition of accessing publications that users recognise and abide by the legal requirements associated with these rights.

- Users may download and print one copy of any publication from the public portal for the purpose of private study or research.

- You may not further distribute the material or use it for any profit-making activity or commercial gain

- You may freely distribute the URL identifying the publication in the public portal 


\title{
Formation and stabilization of reversed austenite in supermartensitic stainless steel
}

\author{
Frank Niessen ${ }^{1,}{ }^{*}$, Flemming B. Grumsen, ${ }^{2,}$, John Hald ${ }^{2, ~ c}$, Marcel A.J. \\ Somers ${ }^{2, d}$ \\ ${ }^{1}$ Technical University of Denmark (DTU), Danish Hydrocarbon Research and Technology Centre \\ (DHRTC), 2800 Kgs. Lyngby, Denmark \\ ${ }^{2}$ Technical University of Denmark (DTU), Department of Mechanical Engineering, 2800 Kgs. Lyngby, \\ Denmark \\ afrannie@dtu.dk, bfbgr@mek.dtu.dk, cjhald@mek.dtu.dk, dsomers@mek.dtu.dk
}

Keywords: Supermartensitic stainless steel, reversed austenite, annealing treatment, microstructure characterization, kinetics modeling, thermal stability

\begin{abstract}
The formation and stabilization of reversed austenite upon inter-critical annealing was investigated in a X4CrNiMo16-5-1 (EN 1.4418) supermartensitic stainless steel by means of scanning electron microscopy, electron backscatter-diffraction, transmission electron microscopy, energydispersive X-ray spectroscopy and dilatometry. The results were supported by thermodynamics and kinetics models, and hardness measurements. Isothermal annealing for $2 \mathrm{~h}$ in the temperature range of 475 to $650^{\circ} \mathrm{C}$ led to gradual softening of the material which was related to tempering of martensite and the steady increase of the reversed austenite phase fraction. Annealing at higher temperatures led to a gradual increase in hardness which was caused by formation of fresh martensite from reversed austenite. It was demonstrated that stabilization of reversed austenite is primarily based on chemical stabilization by partitioning, consistent with modeling results.
\end{abstract}

Introduction. Supermartensitic stainless steels are lath martensitic steels with ultra-low interstitial content and are based on the Fe-Cr-Ni system [1]. The alloy grade became popular in the oil and gas industry as a low cost alternative to highly alloyed duplex stainless steels in pipeline applications [2]. The strength and toughness of the material is based on formation of reversed austenite from lath martensite during inter-critical annealing [3-6]. Annealing leads to effective grain refinement by formation of a two phase structure of soft austenite and hard tempered martensite. Such structure is effective in hindering dislocation-movement during plastic deformation and furthermore exhibits a prolonged plastic regime by transformation of austenite to martensite during plastic straining, a mechanism known as transformation induced plasticity (TRIP) [7-9].

The presented study aims at the clarification of mechanisms involved in formation, growth and stabilization of reversed austenite in supermartensitic stainless steel by a multi-angle approach, using microstructure characterization, in-situ phase quantification, mechanical testing and thermodynamics and kinetics modeling.

Procedures. Materials and heat-treatments. The chemical composition of the tested steel is given in Table 1. Specimens $4 \mathrm{~mm}$ in thickness were sliced from an extruded bar of $\varnothing 10 \mathrm{~mm}$. Specimens for scanning electron microscopy and electron backscatter diffraction were ground and subsequently electro-polished in Struers A2 electrolyte at $20 \mathrm{~V}$ for $30 \mathrm{~s}$. The specimens for transmission electron microscopy analysis were prepared by electrolytic twinjet thinning with $10 \%$ perchloric acid in ethanol at $-20{ }^{\circ} \mathrm{C}$. Prior to investigation the material was normalized for $1800 \mathrm{~s}$ at $1000{ }^{\circ} \mathrm{C}$ in $\mathrm{Ar}$ at atmospheric pressure. The average heating and average cooling rate down to $200{ }^{\circ} \mathrm{C}$ were 45 and 70 
$\mathrm{Kmin}^{-1}$, respectively. The material was annealed in the temperature range of 450 to $900{ }^{\circ} \mathrm{C}$ in steps of $25^{\circ} \mathrm{C}$. Specimens for dilatometry were machined to cylinders of $\varnothing 4 \times 10 \mathrm{~mm}$ with the dilatation axis parallel to the extrusion direction and normalized at $920^{\circ} \mathrm{C}$ for $600 \mathrm{~s}$.

The Vickers-hardness of the specimens was measured with a Wolpert Dia Testor 2Rc according to ASTM E 92 [10]. A load of $30 \mathrm{kgf}$ was applied for $15 \mathrm{~s}$. The presented hardness values are the average of three indents per specimen.

Microstructure characterization. Scanning electron microscopy (SEM) was carried out on an FEI Helios EBS3. Backscatter imaging with a large field backscatter electron detector was applied with $15 \mathrm{kV}$ acceleration voltage, $5.5 \mathrm{nA}$ beam current and $4 \mathrm{~mm}$ working distance.

In order to analyze the orientation relationship of reversed austenite and lath martensite Electron backscatter diffraction (EBSD) was applied. A FEI Helios EBS3 equipped with an EDAX Hikari EBSD camera was used for this purpose. The measurements were carried out at a working distance of $8 \mathrm{~mm}$, an acceleration voltage of $18 \mathrm{kV}$, a beam current of $5.5 \mathrm{nA}$ and a step-size of $100 \mathrm{~nm}$. Data was acquired and processed with the TSL EBSD Data Collection System. Phase- and inverse pole figure maps were cleaned by grain confidence index standardization and a single dilation iteration (Tolerance: 5, Min. size: 3) as well as a confidence index threshold of 0.1 .

The microscope used for bright-field- and dark-field-imaging, and selected area electron diffraction in Transmission electron microscopy (TEM) was a JEOL 3000F with a field emission gun source operated at $300 \mathrm{kV}$ acceleration voltage. Diffraction patterns were analyzed with the JEMS electron microscopy simulation software.

The microscope used for energy filtered TEM (EFTEM) and EDS-analysis in scanning TEM (STEM) was a Tecnai $\mathrm{T}_{20 \mathrm{G}^{2}}$ with a thermionic $\mathrm{LaB}_{6}$ filament operated at $200 \mathrm{kV}$ acceleration voltage. Energy-filtered TEM was carried out to analyze the distribution of $\mathrm{Ni}$ in the microstructure after annealing. This was done by acquiring a jump-ratio map of the $\mathrm{Ni}_{3}$ edge at $855 \mathrm{eV}$ applying energy windows of $25 \mathrm{eV}$. EDS-analysis was carried out excluding $\mathrm{C}, \mathrm{N}, \mathrm{P}$ and $\mathrm{S}$ from quantification. The STEM-EDS-measurements were quantified from approx. 55.000 counts per measurement point and manual background-correction.

Dilatometry. Dilatometry was applied to follow the martensite-to-austenite formation in-situ. The material was therefore heated to maximum temperatures of 625 to $700{ }^{\circ} \mathrm{C}$ with $15 \mathrm{~K}$. $\mathrm{min}^{-1}$ and immediately cooled to room temperature with $15 \mathrm{~K}_{\mathrm{min}}{ }^{-1}$. The measurements were carried out in a Bähr DIL 805A/D dilatometer, in which specimens were heated through induction and the temperature was monitored with a thermo-couple spot-welded to the specimen surface. The measurements were carried out in He at atmospheric pressure to avoid oxidation. The phase-fractions of austenite and martensite were determined by using the lever-rule which uses base-lines of the expansion of pure austenite and martensite to estimate the fraction of the phases in a two-phase microstructure. The baseline for pure martensite was extrapolated from the dilatometry curve before austenite formation occurred; the baseline for pure austenite was determined by a dilatometry measurement of cooling from the austenite region at $950{ }^{\circ} \mathrm{C}$. The amount of retained austenite after martensite transformation was measured 5 vol.\% with X-ray diffraction and was manually added as an initial fraction to the quantification. The lever-rule assumes that expansion of the specimen parallel

Table 1- Chemical composition of the investigated X4CrNiMo16-5-1 SMSS balanced with Fe (wt.\%), determined with Optical emission spectroscopy (OES)

\begin{tabular}{ccccccccc}
$\mathrm{C}$ & $\mathrm{N}$ & $\mathrm{Cr}$ & $\mathrm{Ni}$ & $\mathrm{Mo}$ & $\mathrm{Mn}$ & $\mathrm{Si}$ & $\mathrm{P}$ & $\mathrm{S}$ \\
\hline 0.03 & 0.037 & 15.00 & 5.80 & 1.03 & 0.86 & 0.39 & 0.025 & 0.008 \\
\hline
\end{tabular}


to the dilatational axis is proportional to the overall volume expansion of the specimen, that the monitored phase transformation does not lead to build-up or release of stresses, and that austenite and martensite are the only present phases in the material. More details to the procedure can be found in Ref. [11]. Additional measurements were carried out in which heating to maximum temperatures of 625 to $700{ }^{\circ} \mathrm{C}$ with $15 \mathrm{~K} . \mathrm{min}^{-1}$ was followed by cooling to $-150{ }^{\circ} \mathrm{C}$ with $15 \mathrm{~K} \cdot \mathrm{min}^{-1}$ and reheating to room temperature with $15 \mathrm{~K} \cdot \mathrm{min}^{-1}$. These measurements were not quantified by the means of the lever-rule method in the sub-zero Celsius regime, since baselines to such low temperature were difficult to estimate.

Thermodynamics and kinetics modeling. Thermodynamics modeling applying the CALPHAD approach [12,13] is a widely established method for prediction of thermodynamic equilibria in multicomponent systems. Such predictions are useful to refine experimental planning and support interpretation of experimental data. In this investigation Thermo-Calc 2015b with the TCFE6 database [14] for iron-based alloys was used to predict phase fractions and compositions at various temperatures.

The kinetics model DICTRA is a module of the Thermo-Calc package which enables 1dimensional kinetics modeling of diffusion controlled transformations in multicomponent systems. [15] In the present investigation DICTRA is used to model the transformation kinetics for isothermal holding at various soaking temperatures, using the mobility database MOB2 [16]. The modelled transformation included the effect of $\mathrm{Cr}, \mathrm{Ni}, \mathrm{Mn}$, Mo and Si balanced with Fe. The model was setup in a linear cell-geometry which was discretized with $1 \mathrm{~nm}$ spatial resolution and was $125 \mathrm{~nm}$ in length, corresponding to approx. half the martensite lath width. More details on the setup of the kinetics model can be found in Ref. $[17,18]$.

Results. The specimen in as-austenitized condition (AA) revealed a hardness of 365 HV (Figure 1). Secondary hardening of the material was found at $475^{\circ} \mathrm{C}$. For annealing temperatures up to $650{ }^{\circ} \mathrm{C}$ the material softened; for annealing temperatures higher than $650{ }^{\circ} \mathrm{C}$ a steady increase in hardness was observed.

Dilatometry. Dilatometry was carried out in order to follow the phase transformation of martensite to austenite in-situ. Figure 2a shows the dilatometry curve for heating to $700{ }^{\circ} \mathrm{C}$ with $15 \mathrm{~K} \cdot \mathrm{min}^{-1}$ and

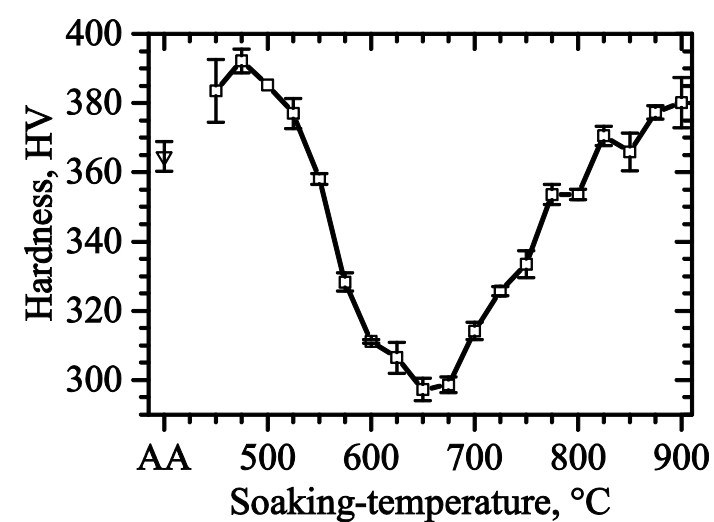

Figure 1 - Hardness for the as-austenitized condition and annealing temperatures 450 to $900{ }^{\circ} \mathrm{C}$ at $2 \mathrm{~h}$ soaking-time. The errorbars indicate the standard deviation from three measurements. immediate cooling to room temperature with $15 \mathrm{~K} . \mathrm{min}^{-}$ ${ }^{1}$. The lines denoted as $\varepsilon_{\alpha}$, and $\varepsilon_{\gamma}$ indicate the baselines of martensite and austenite as a single-phase material, respectively, so that the lever-rule can be applied to determine the transformed fraction. The result of this quantification method is shown in Figure 2b, in which the austenite fraction over temperature is shown for heating and immediate cooling with $15 \mathrm{~K} \cdot \mathrm{min}^{-1}$. For heating to 650 and $675^{\circ} \mathrm{C}$ austenite fractions of 20 and 37 vol.\% were stabilized to room temperature. Heating to $700{ }^{\circ} \mathrm{C}$ led to a fraction of $59 \mathrm{vol} . \%$ during cooling which then partially transformed to new martensite at the martensite start temperature $75{ }^{\circ} \mathrm{C}$, leaving 37 vol.\% of austenite untransformed. The sudden dilation 


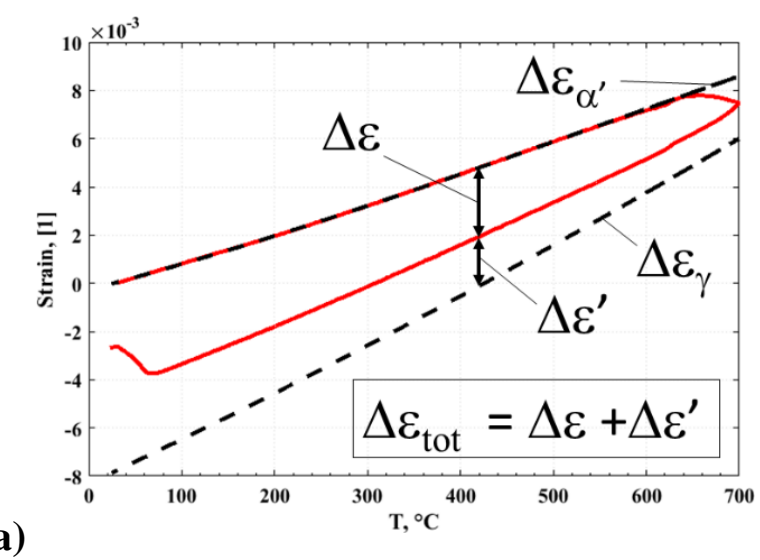

b)

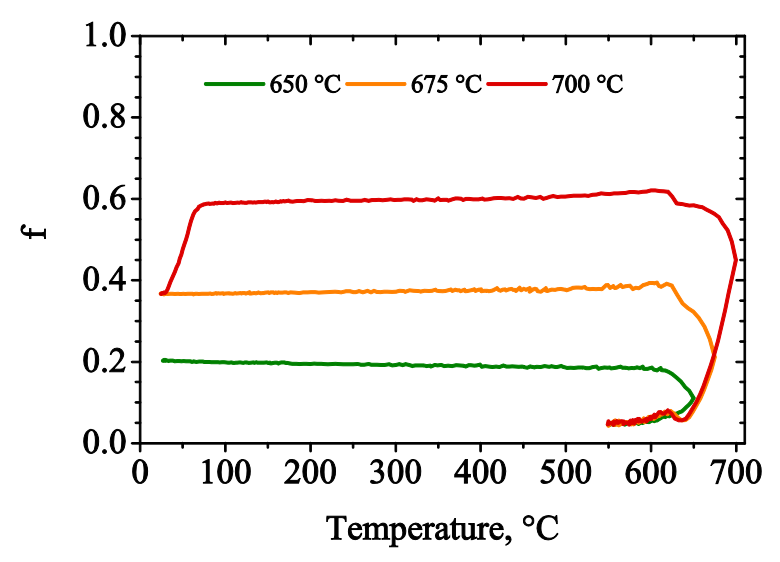

Figure 2 - Dilatometry: (a) Dilatometry curve of heating at $15 \mathrm{~K} \cdot \mathrm{min}^{-1}$ to $700{ }^{\circ} \mathrm{C}$ and immediate cooling to $2{ }^{\circ} \mathrm{C}$ at $15 \mathrm{~K} . \mathrm{min}^{-1}$; the lines denoted as $\varepsilon_{\alpha}$, and $\varepsilon_{\gamma}$ indicate the baselines of martensite and austenite, respectively, for phase-quantification by the lever-rule; (b) phase fraction of austenite over temperature according to the lever-rule for heating and immediate cooling at $15 \mathrm{~K} \cdot \mathrm{min}^{-1}$

at approx. $620{ }^{\circ} \mathrm{C}$ during heating and cooling are artefacts caused by the magnetic transition at the Curie-temperature.

The results for sub-zero Celsius dilatometry down to $-150{ }^{\circ} \mathrm{C}$ revealed that reversed austenite which is formed up to $650{ }^{\circ} \mathrm{C}$ was stable upon cryogenic cooling. Heating to $675{ }^{\circ} \mathrm{C}$ and subsequent cooling led to the formation of 26 vol.\% austenite which remained stable down to $-150{ }^{\circ} \mathrm{C}$. Upon reheating 3 vol.\% of austenite transformed to martensite from $-60{ }^{\circ} \mathrm{C}$ to $30{ }^{\circ} \mathrm{C}$. Heating to $700{ }^{\circ} \mathrm{C}$ yielded 59 vol.\% of austenite upon cooling to $58{ }^{\circ} \mathrm{C}$, where martensite transformation started. 39 vol. $\%$ of reversed austenite was stable at room-temperature and only 25 vol. $\%$ at $-75{ }^{\circ} \mathrm{C}$, where martensite formation stopped.

Microstructure characterization. Investigation of electro-polished specimens was carried out with a large field backscatter electron detector. Strong contrast between the austenite grains (white) and the lath martensite matrix was observed (Figure 3a). Since no major difference in atomic number is expected, the contrast is presumably orientation related. The grain orientation affects the electron

a)

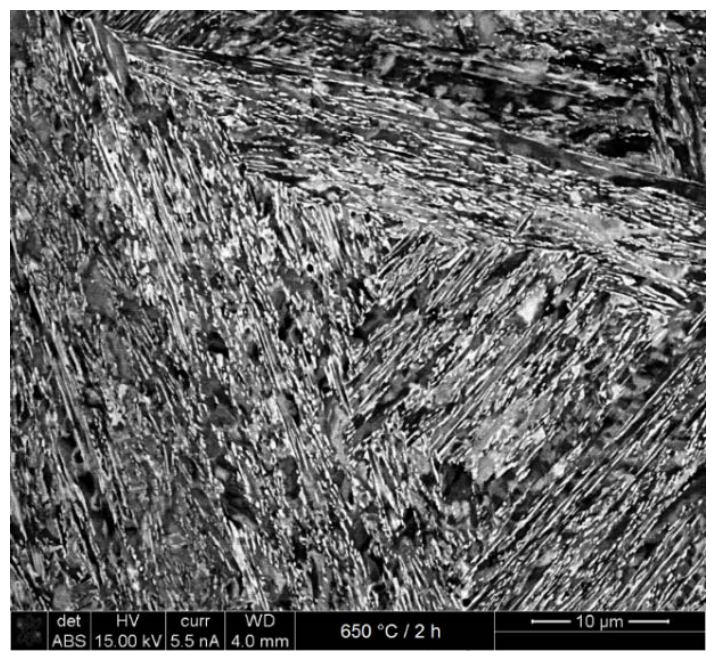

b)

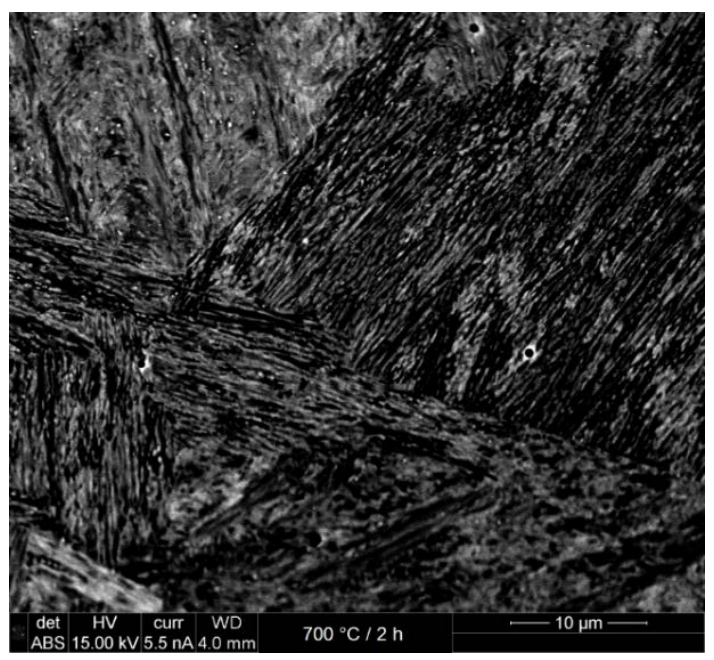

Figure 3 - BSE-imaging: (a) Condition $650^{\circ} \mathrm{C} / 2 \mathrm{~h}$ showing two phase microstructure of lathmartensite (grey) and lamellar inter-lath reversed austenite (white); (b) Condition $700^{\circ} \mathrm{C} / 2 \mathrm{~h}$ showing loss of the two-phase contrast, indicating transformation of reversed austenite to fresh martensite upon cooling. 
a)

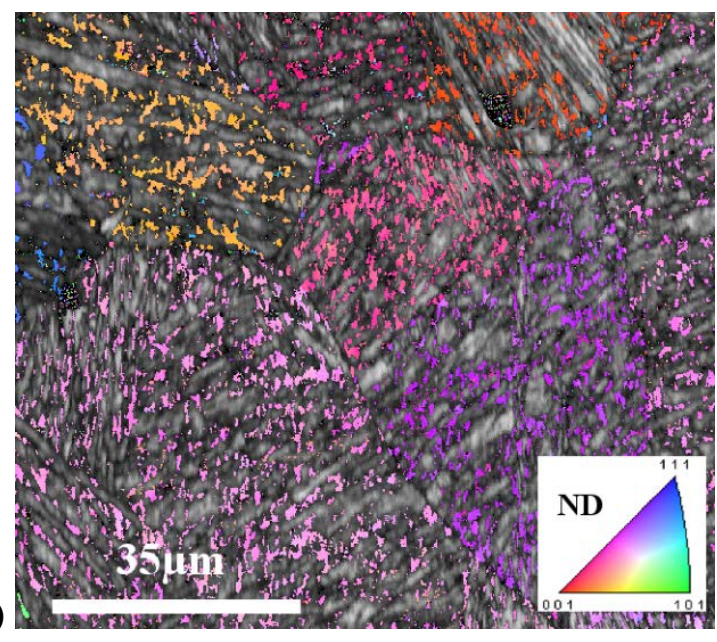

b)

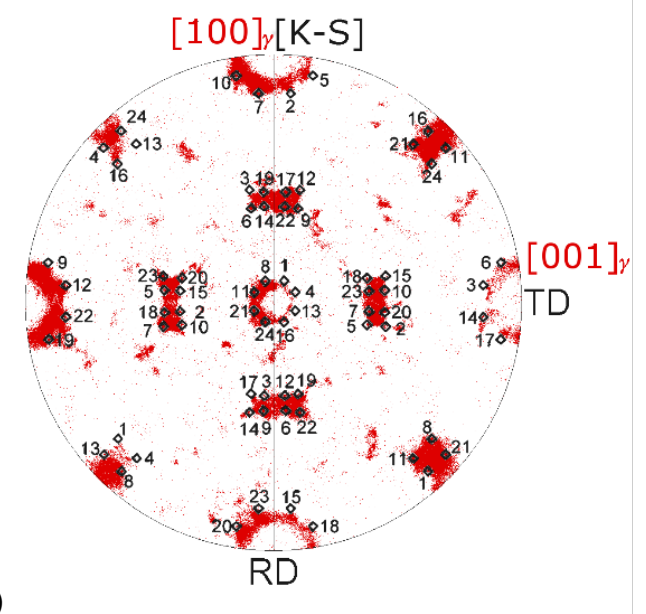

Figure 4 - EBSD: (a) Inverse pole-figure map of austenite superimposed on image-quality map. It is evident that reversed austenite inherits the orientation of the prior austenite grains; (b) Inverse pole-figure of rotated prior austenite grain into [100]-direction for direct comparison with the numbered variants of the Kurdjumov-Sachs orientation relationship (numbering convention according to Ref. [20]).

penetration into the specimen through diffraction effects and thus has an effect on the backscatter electron yield.[19] For tempering at $700{ }^{\circ} \mathrm{C}$ this contrast was weakened which indicates the formation of martensite during cooling to room-temperature. In order to study the orientation relationship between reversed austenite and the tempered martensite matrix, orientation-data of several prior austenite grains were isolated. Each data-set was then rotated by aligning the $<100>$ directions of austenite parallel to the specimen axes, so that the tempered martensite variants could be compared with the Kurdjumov-Sachs (KS) orientation relationship in an inverse pole-figure (Figure 4b). The measured orientation data is in excellent agreement with the KS orientation relationship. In each grain some martensite variants were represented more frequently than in others.

Specimens in the annealing conditions $650^{\circ} \mathrm{C} / 2 \mathrm{~h}$ and $700^{\circ} \mathrm{C} / 2 \mathrm{~h}$ were examined with TEM. Applying selected area electron diffraction (SAED) and dark field imaging it was found that the specimen annealed at $650{ }^{\circ} \mathrm{C} / 2 \mathrm{~h}$ consists of a tempered martensite matrix with reversed austenite lamellas of 80 to $140 \mathrm{~nm}$ width. In the applied specimen tilt austenite was in Bragg-condition and thus appears in dark contrast in the bright-field image in Figure 5a, as evidenced with dark-field imaging with the corresponding SAED pattern. Consistent with results from EBSD-analysis, SAED revealed that austenite formed in Kurdjumov-Sachs relationship with martensite: $[\overline{1} 12]_{\text {bcc }} \|[\overline{11} 2]_{\text {fcc }}$, (110)bcc $\|$ (111)fcc. Figure 6b and Figure 6c show selected area electron diffraction patterns with the correspondent dark-field images of tempered and newly formed martensite, respectively, of the $700^{\circ} \mathrm{C} / 2 \mathrm{~h}$ condition. The analyzed martensite variants hold the following orientation relationship: $[111]_{\text {bcc }}\left\|[110]_{\text {bcc }},(1 \overline{1} 0)_{\text {bcc }}\right\|(1 \overline{1} 0)_{\text {bcc }}$. Newly formed martensite could be distinguished from tempered martensite by the dislocation density which is clearly visible from the bright-field image, which was acquired before applying specimen tilt for diffraction analysis (Figure 6a).

Figure 7a shows a jump-ratio map of the $\mathrm{Ni} \mathrm{L}_{3}$ edge from which partitioning of $\mathrm{Ni}$ between austenite and martensite is evident. Figure 7b shows the EDS-quantification of a line-scan over an austenite lamella in STEM and confirms partitioning of Ni between austenite and martensite. The austenite lamella is shown in the HAADF image. 
a)

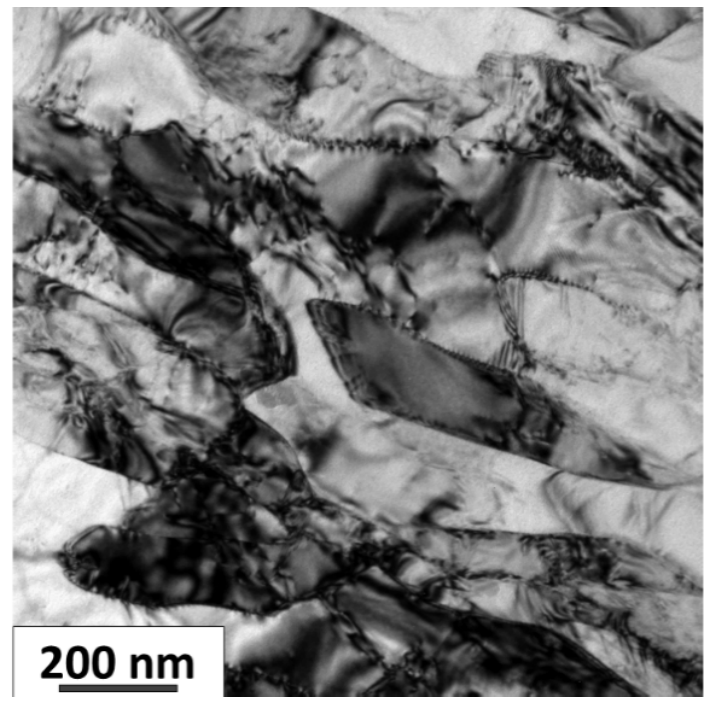

b)

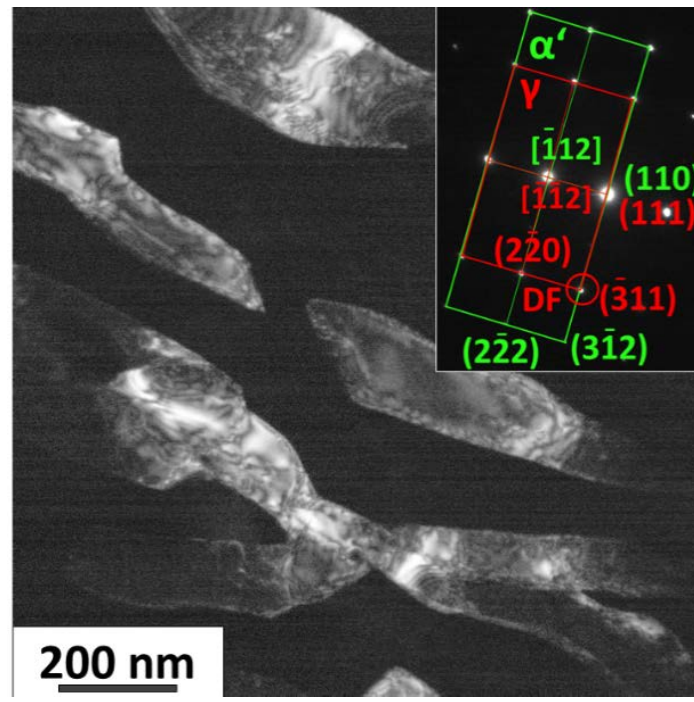

Figure 5 - TEM, condition $650^{\circ} \mathrm{C} / 2 \mathrm{~h}$ : (a) Bright-field image of austenite (dark) and tempered martensite (bright); (b) Selected area electron diffraction pattern and dark-field image of austenite

a)

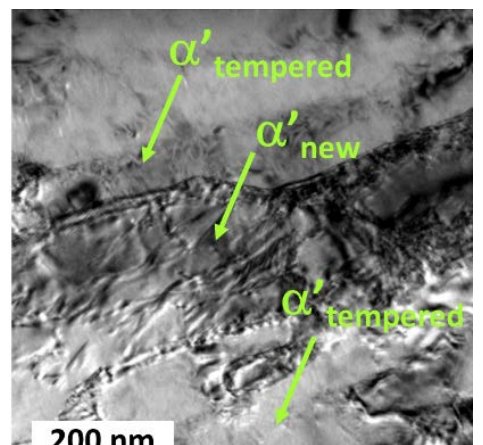

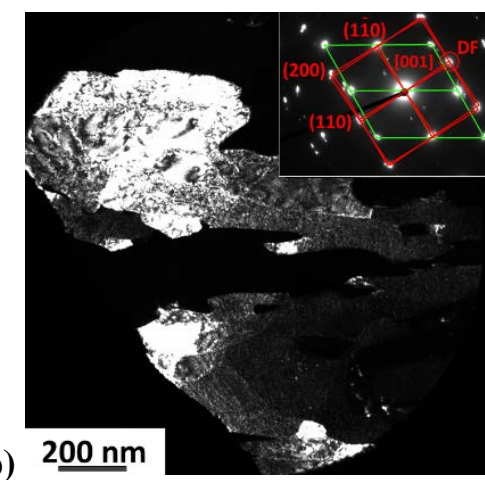

b)

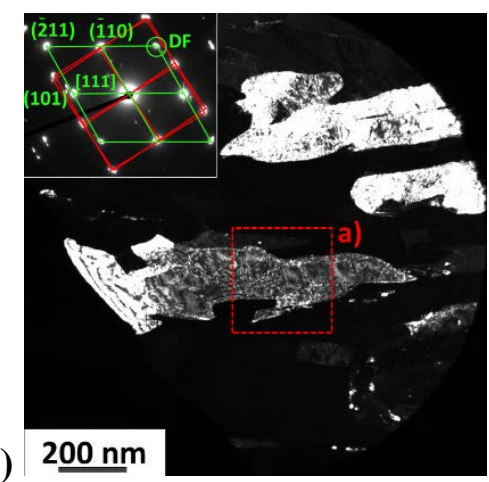

c)

Figure 6 - TEM, condition $700^{\circ} \mathrm{C} / 2 \mathrm{~h}$ : (a) bright-field image of area a) in Figure $6 \mathrm{c}$ before tilting into the [111] zone axis for diffraction, showing tempered and newly formed martensite; (b) Selected area electron diffraction pattern and dark-field image of tempered martensite; (c) Selected area electron diffraction pattern and dark-field image of a newly formed martensite lath; the dark round corners of the dark-field images are the objective aperture

a)

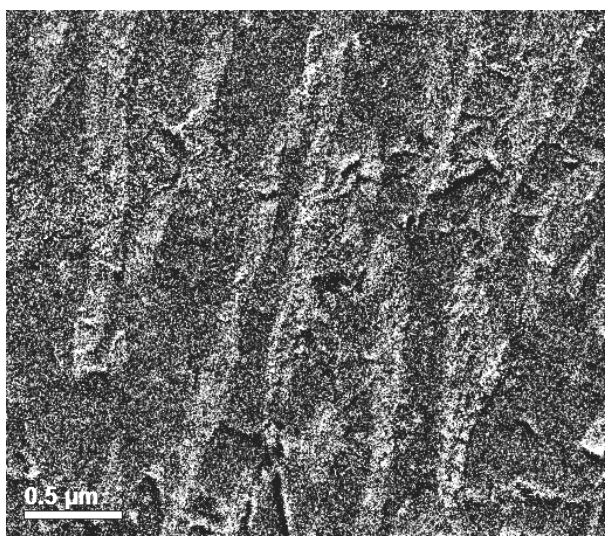

b)

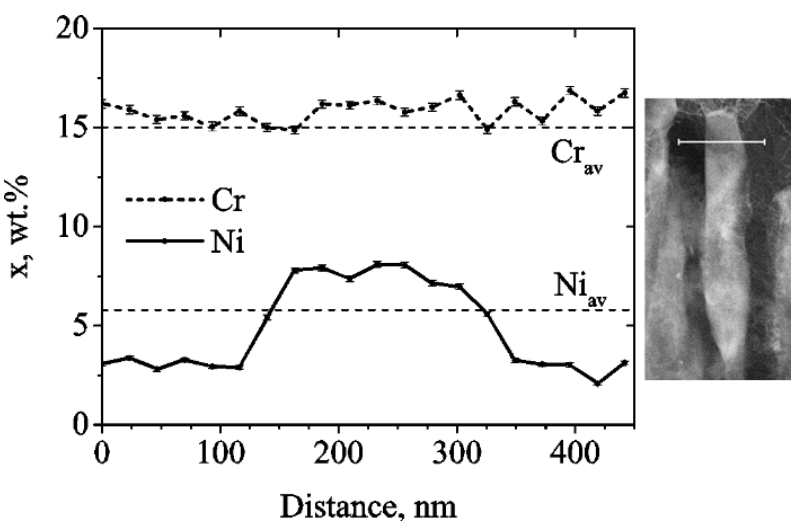

Figure 7 - TEM $650^{\circ} \mathrm{C} / 2 \mathrm{~h}$ : (a) Jump-ratio map of the $\mathrm{Ni}_{3}$ edge showing the distribution of $\mathrm{Ni}$, indicating partitioning of $\mathrm{Ni}$ between reversed austenite and martensite; (b) EDS quantification of $\mathrm{Ni}$ and $\mathrm{Cr}$-content from line-scan over austenite lamella, which is shown in the STEM-HAADF image; The error-bars indicate the uncertainty from EDS data-processing.

Thermodynamics and kinetics modeling. The kinetics of austenite formation for isothermal holding at 650,675 and $700{ }^{\circ} \mathrm{C}$ was predicted with kinetics modeling. It is evident from Figure 8a that the martensite-to-austenite transformation accelerates with increasing temperature so that less time is 
required to reach the equilibrium phase fraction, as indicated by intersection with the grey background. At the $2 \mathrm{~h}$ mark (vertical dotted line in Figure 8a), which corresponds to the holding time in the experiments, the transformation at $675{ }^{\circ} \mathrm{C}$ is just about to reach equilibrium. According to kinetics modeling annealing at $700{ }^{\circ} \mathrm{C}$ would only require approx. $15 \mathrm{~min}$ to reach equilibrium, while holding at $650^{\circ} \mathrm{C}$ would require $8 \mathrm{~h}$.

The contents of the main alloying elements $\mathrm{Ni}$ and $\mathrm{Cr}$ in ferrite (b.c.c.) and austenite (f.c.c.) according to thermodynamic equilibrium are predicted as a function of temperature in Figure 8b. The figure indicates that the concentrations of $\mathrm{Cr}$ and $\mathrm{Ni}$ in ferrite and austenite diverge progressively from the average alloy composition with decreasing phase-fraction.

Discussion. Investigation of austenite reversion and stability by use of correlative methods reveals insight into some of the mechanisms involved in formation and stabilization of reversed austenite. The microstructural evolution during annealing and cooling will accordingly be discussed based on the results of the applied techniques.

Orientation of reversed austenite and nucleation. Correlative microstructure characterization by SEM and TEM analysis (Figure 3 and Figure 5, respectively) revealed that lamellar austenite forms in-between martensite laths. EBSD analysis reveals that the orientation relationship between this reversed austenite and the existing lath martensite complies with the Kurdjumov-Sachs orientation relation (Figure 4b), consistent with the results from selected area electron diffraction in TEM (Figure 5). Furthermore, reversed austenite holds a common orientation within a prior austenite grain (and its twins), strongly suggesting that reversed austenite inherits the original orientation of the austenite present prior to martensite formation (Figure 4a). This effect is commonly referred to as the austenite memory effect. The effect could either indicate that austenite grows from inter-lath retained austenite films of a few atomic layers in thickness, i.e. without nucleation in the classical sense, [21] or that variant selection limits the number of possible variants to the observed ones. [22] An internal study using Transmission Kikuchi diffraction showed that the 5 vol.\% of retained austenite present before

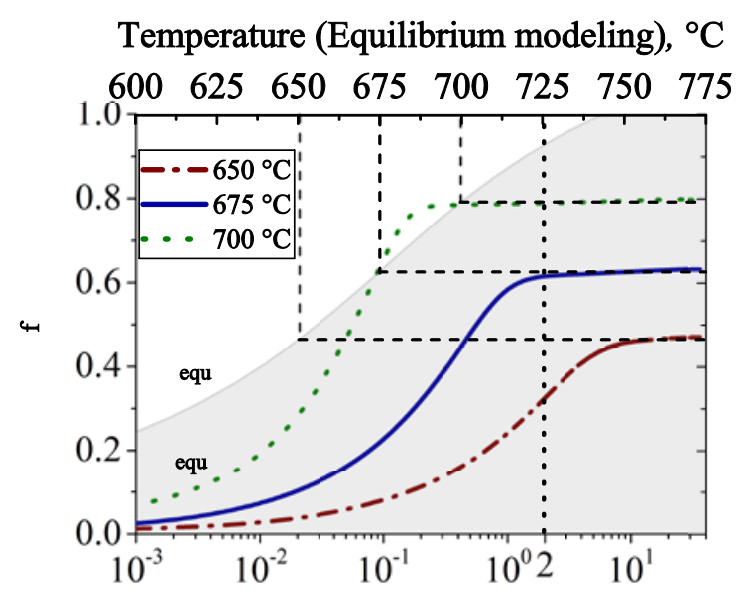

a)

Time (Kinetics modeling), $\mathrm{h}$

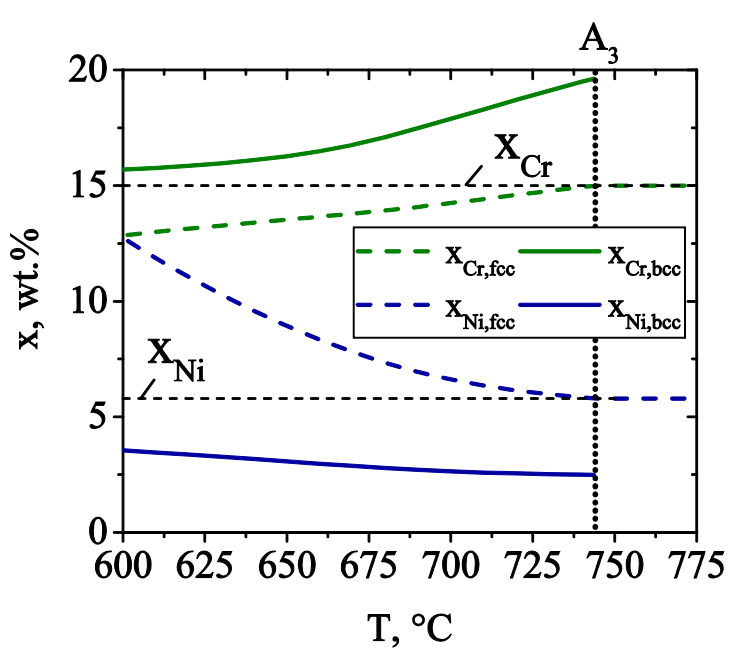

b)

$\mathrm{T},{ }^{\circ} \mathrm{C}$

Figure 8 - (a) Kinetics of austenite formation for isothermal holding at 650,675 and $700{ }^{\circ} \mathrm{C}$ predicted with kinetics modeling; the grey area indicates the thermodynamically stable phase fraction of austenite over temperature; (b) Equilibrium composition of austenite and martensite (ferrite) over temperature. The horizontal dashed lines reflect the alloy content of $\mathrm{Ni}$ and $\mathrm{Cr}$, the $\mathrm{A}_{3}$-temperature is the temperature at which only f.c.c. is thermodynamically stable. The intersection of the b.c.c. alloying contents at $600{ }^{\circ} \mathrm{C}$ is incidental 
reversed austenite formation is inhomogeneously distributed in a chunky morphology, rather than as an inter-lath film. Since inter-lath retained austenite films could be below the detection limit of the techniques used in this investigation, no distinction can be made between the above-mentioned mechanisms for the observed austenite memory effect.

Morphology of reversed austenite. As stated in the previous section, reversed austenite forms as lamellae in-between martensite laths. The lamella width increases with increasing annealing temperature, consistent with a steady increase in austenite phase fraction with temperature, as expected from thermodynamic equilibrium (Figure 8a). The transition from lamellar austenite in a two-phase microstructure to a classic one-phase austenite microstructure with few large grains with increasing time and temperature was reported to occur by steady spheroidization of lamellae, homogeneous nucleation of spherical grains and subsequent grain growth [23].

Phase fraction of reversed austenite. Figure 1 shows steady softening of the material with increasing annealing temperature from 475 to $650{ }^{\circ} \mathrm{C}$ for $2 \mathrm{~h}$ of soaking time. The softening of the material is both related to softening of martensite by tempering and a progressive increase in austenite phase fraction, and indicates that annealing at $650^{\circ} \mathrm{C} / 2 \mathrm{~h}$ yields the maximum amount of austenite. The observed increase in austenite fraction correlates with an increase in thermodynamic equilibrium phase-fraction at the applied annealing temperatures (Figure 8a). As indicated by the results from kinetics modeling, $2 \mathrm{~h}$ of soaking time seems feasible to reach a state close to thermodynamic equilibrium from $650{ }^{\circ} \mathrm{C}$ and above. This indicates that, possibly, further softening could have been reached at temperatures below $650{ }^{\circ} \mathrm{C}$ if longer soaking times had been applied. When annealing at $675{ }^{\circ} \mathrm{C}$ and above the material revealed a steady increase in hardness, indicating a reduction in austenite phase fraction at room-temperature.

In-situ monitoring of the phase fraction with dilatometry showed stabilization of austenite up to 37 vol.\% for heating to $675^{\circ} \mathrm{C}$. In the dilatometry experiments no holding time was applied at the maximum temperature which led to the maximum fraction of stable austenite at $675{ }^{\circ} \mathrm{C}$ rather than $650{ }^{\circ} \mathrm{C}$ (Figure 2b). Heating to $700{ }^{\circ} \mathrm{C}$ resulted in an even higher fraction of austenite at the annealing temperature, but did not result in an increase in austenite phase fraction at room-temperature because of a transformation to martensite at $75^{\circ} \mathrm{C}$.

Thermal stability of reversed austenite. The results and the discussion to this point indicate that austenite can be stabilized to a certain amount to room temperature by applying a suitable annealing treatment. Results from hardness measurements and dilatometry show that applying a relatively high annealing temperature leads to a loss in stable phase fraction at room temperature. The mechanisms which lead to stabilization, and eventual loss of stability should therefore be discussed in more detail. In the inter-critical region, i.e. the region at which both ferrite and austenite are thermodynamically stable, the equilibrium phase-compositions of ferrite (martensite) and austenite differ from the average alloy-composition. The lower the equilibrium phase-fraction, the more enrichment in phasestabilizing elements is thermodynamically required. This effect is clearly visible for the $\mathrm{Ni}$ and $\mathrm{Cr}$ content of austenite (f.c.c.) and ferrite (b.c.c.) over temperature in thermodynamic equilibrium (Figure 8b). Following the $\mathrm{Ni}$ and $\mathrm{Cr}$ contents of both phases towards the $\mathrm{A}_{3}$-temperature it is evident that the austenite composition approaches the alloy composition, whereas the ferrite composition drifts towards increased $\mathrm{Cr}$ and decreased $\mathrm{Ni}$ content. Likewise substantial enrichment in $\mathrm{Ni}$ and depletion in $\mathrm{Cr}$ is necessary for austenite to form at substantially lower temperatures than the $\mathrm{A}_{3}$-temperature. At this point it becomes clear that the drastic decrease of the rate of the martensite-to-austenite transformation with lower annealing temperature predicted by kinetics modeling is both owed to a 
decrease in general diffusion kinetics, and higher required atomic fluxes to establish the partitioning of alloying elements between the two phases (Figure 8a).

Since austenite forms by diffusion at low heating rates and thus also during isothermal annealing $[3,17]$, it can be assumed that the composition of austenite in the experimental annealing is close to the predicted equilibrium composition in Figure 8b. In order to evaluate the stability of reversed austenite at different annealing temperatures, the $\mathrm{M}_{\mathrm{s}}$-temperature of reversed austenite with equilibrium composition as a function of temperature is calculated with two empirical formulas. The first formula by Folkhard was specifically designed for soft martensitic steels in welding lines [24]:

$$
\begin{gathered}
M_{s, F}=492-125 \times(w t . \% C)-65.5 \times(w t . \% M n)-10 \times(w t . \% C r) \\
-29 \times(w t . \% N i)
\end{gathered}
$$

The second formula by Gooch was also developed for the use on supermartensitic stainless steels in welding applications [25]:

$$
\begin{aligned}
M_{s, G}=540- & 497 \times(w t . \% C)-6.3 \times(w t . \% M n)-36.3 \\
& \times(w t . \% N i)-10.8 \times(w t . \% C r)-46.6 \times(w t . \% M o)
\end{aligned}
$$

The kinetics model was run without contribution of interstitial elements for reasons of numeric stability; for the sake of consistency the equilibrium calculations and subsequently the $\mathrm{M}_{\mathrm{s}^{-}}$ temperature calculations were therefore also carried out without the effect of $\mathrm{N}$ and C. Figure 9 shows the resulting graphs for the $\mathrm{M}_{\mathrm{s}}$-temperature as a function of annealing temperature for compositions from thermodynamic equilibrium (lines) and from EDS analysis of the annealing condition $650^{\circ} \mathrm{C} / 2 \mathrm{~h}$ from Figure $7 \mathrm{~b}$ (data points). It is evident that reversed austenite becomes less stable with increasing annealing temperature and that the $\mathrm{M}_{\mathrm{s}}$-temperature with increasing phase fraction of austenite approaches the average $\mathrm{M}_{\mathrm{s}}$-temperature of the alloy.

The $\mathrm{M}_{\mathrm{s}}$-temperature of the investigated alloy on cooling after austenitization was determined as $135^{\circ} \mathrm{C}$ with dilatometry; the predicted temperatures by both formulas deviate approx. $20^{\circ} \mathrm{C}$ from

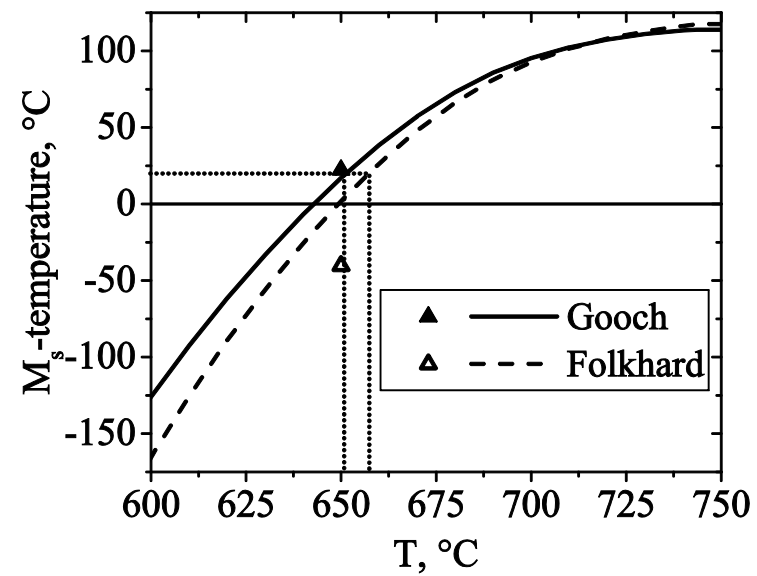

Figure 9 - Martensite start temperature based on empiric formulae of Gooch [25] and Folkhard [24] applied on the equilibrium composition of austenite (Figure $8 b$ ) and the EDS-results at $650{ }^{\circ} \mathrm{C}$ (Figure $\left.7 \mathrm{~b}\right)$. The dotted lines indicate the critical annealing temperatures for austenite stability at roomtemperature (martensite start temperature 20 $\left.{ }^{\circ} \mathrm{C}\right)$ this value. The formulae by Gooch and Folkhard predicted the critical temperatures for stability of austenite at room-temperature to 651 and $657^{\circ} \mathrm{C}$ (cf. Figure 9), respectively. This is well in line with the condition of lowest hardness, and thus maximum austenite phase-fraction, for tempering at $650{ }^{\circ} \mathrm{C}$ for $2 \mathrm{~h}$ (Figure 1). The dilatometry measurements to sub-zero Celsius temperature are in qualitative agreement with the prediction of the empirical formulae. Quantitative comparison is not feasible as not enough soaking time at the maximum temperature was applied to approach thermodynamic equilibrium.

These observations support the hypothesis that stabilization of reversed austenite is mainly a chemical stabilization. Furthermore it is anticipated that the lamellar structure of reversed austenite leads to additional mechanical stabilization. Annealing at increased temperature 
and time would lead to a steady spheroidization of reversed austenite which would reduce the amount of strain energy needed for martensite transformation and reduce mechanical stabilization. This effect is discussed in further depth in Ref. [23].

Conclusions. The mechanisms involved in the formation and stabilization of reversed austenite in supermartensitic stainless steel was studied in a multi-angle approach. The main conclusions are:

- Austenite can be stabilized by isothermal annealing and leads to softening of the material. The lowest hardness, corresponding to the maximum phase fraction of austenite, was measured for annealing $2 \mathrm{~h}$ at $650^{\circ} \mathrm{C}$.

- Thermodynamics modeling was used to demonstrate that austenite is increasingly chemically stabilized the further it forms below the $\mathrm{A}_{3}$-temperature. Annealing above $650{ }^{\circ} \mathrm{C}$ correspondingly leads to a gradual decrease in fraction austenite and to an increase in hardness.

- The stability of reversed austenite by chemical stabilization was analyzed by equilibrium compositions of austenite at different temperatures and empirical formulas for the $\mathrm{M}_{\mathbf{s}}$ temperature. The analysis yielded good agreement with the experimental results.

Acknowledgements. The Danish Underground Consortium is gratefully acknowledged for financial support to the Danish Hydrocarbon Research Center (DHRTC). Olaf Kessler, Michael Reich, and Kristin Aurich are acknowledged for their support with the dilatometry activities at Rostock University.

\section{References}

[1] A.W. Marshall, J.C.M. Farrar, Weld. World 45 (2001) 19-42.

[2] L.M. Smith, M. Celant, in:, Supermartensitic Stainl. Steels 1999, 1999, pp. 66-73.

[3] D.-S. Leem, Y.-D. Lee, J.-H. Jun, C.-S. Choi, Scr. Mater. 45 (2001) 767-772.

[4] H.J. Niederau, in:, G. Behal, A.S. Melilli (Eds.), Stainl. Steel Cast., ASTM, Bal Harbour, Florida, 1982, pp. 382393.

[5] M. Al Dawood, I.S. El Mahallawi, M.E. Abd El Azim, M.R. El Koussy, Mater. Sci. Technol. 20 (2004) $363-369$.

[6] D. Ye, J. Li, W. Jiang, J. Su, K. Zhao, Mater. Des. 41 (2012) 16-22.

[7] P.D. Bilmes, M. Solari, C.. Llorente, Mater. Charact. 46 (2001) 285-296.

[8] M. Karlsen, J. Hjelen, Ø. Grong, G. Rørvik, R. Chiron, U. Schubert, E. Nilsen, Mater. Sci. Technol. 24 (2008) 64-72.

[9] T. LeBrun, T. Nakamoto, K. Horikawa, H. Kobayashi, Mater. Des. 81 (2015) 44-53.

[10] E.L. Tobolski, A. Fee, in:, Mech. Test. Eval. 8, ASM Handbook, ASM Int., 2000, p. p 203-220.

[11] F. Niessen, M. Villa, D. Apel, O. Keßler, M. Reich, J. Hald, M.A.J. Somers, F. Nießen, M. Villa, D. Apel, O. Keßler, M. Reich, J. Hald, M.A.J. Somers, Mater. Sci. Forum 879 (2017) 1381-1386.

[12] P.J. Spencer, Calphad Comput. Coupling Phase Diagrams Thermochem. 32 (2008) 1-8.

[13] L. Kaufman, H. Bernstein, Acad. Press (1970) 334 s.

[14] (n.d.).

[15] A. Borgenstam, A. Engström, L. Höglund, J. Ågren, J. Phase Equilibria 21 (2000) 269-280.

[16] (n.d.).

[17] F. Niessen, M. Villa, J. Hald, M.A.J. Somers, Mater. Des. 116 (2017).

[18] F. Niessen, N.S. Tiedje, J. Hald, Mater. Des. 118 (2017) 138-145.

[19] R.F. Egerton, Physical Principles of Electron Microscopy - An Introduction to TEM, SEM and AEM, 2005.

[20] S. Morito, H. Tanaka, R. Konishi, T. Furuhara, T. Maki, Acta Mater. 51 (2003) 1789-1799.

[21] L. Liu, Z.-G. Yang, C. Zhang, J. Alloys Compd. 577 (2013) 654-660.

[22] N. Nakada, T. Tsuchiyama, S. Takaki, S. Hashizume, ISIJ Int. 47 (2007) 1527-1532.

[23] S. Zhang, P. Wang, D. Li, Y. Li, Mater. Des. 84 (2015) 385-394.

[24] E. Folkhard, in:, Weld. Metall. Stainl. Steels, 1988, pp. 98-181.

[25] T.G. Gooch, Weld. Inst. Researach Bull. (1977) 343-349. 